\title{
Hard Determinism, Remorse, and Virtue Ethics
}

\section{Ben Vilhauer \\ Claremont McKenna College}

Hard determinists hold that moral responsibility is incompatible with determinism, that determinism is true for all human actions, and that human beings are consequently not morally responsible for any of their actions. ${ }^{1}$ It is often objected that, since hard determinists reject the idea of moral responsibility, they have to reject our current practices of punishing wrongdoers. The concepts of desert and moral responsibility go hand in hand-one cannot deserve to be punished for something unless one is morally responsible for it. So if no one is morally responsible, no one deserves to be punished, and punishment cannot be justified if it is not deserved. This objection extends not just to punishment inflicted upon wrongdoers by others but also to punishment wrongdoers inflict upon themselves. Remorse is often taken to be a kind of self-inflicted punishment, a way of imposing emotional suffering upon oneself because one takes oneself to deserve it. Proponents of this objection think it is absurd to claim that we have to reject all these ways of responding to wrongful actions, and since they think hard determinists have to claim this, they think we should reject hard determinism.

This objection depends upon a retributive interpretation of punishment. According to retributivism, punishment must be justified in terms of what the agent deserves. Hard determinists can respond to this objection by rejecting retributivism and adopting consequentialism about punishment instead. ${ }^{2}$ According to consequentialism, punishment must be justified in terms of its beneficial behavioral consequences. For example, imprisonment has the beneficial behavioral consequences of preventing

Ben Vilhauer is Visiting Assistant Professor at Claremont McKenna College. He received a Ph.D. from the University of Chicago in 2002. His recent publications include "Can We Interpret Kant as a Compatibility about Determinism and Moral Responsibility?" (British Journal for the History of Philosophy) and "On a Tension in Diamond's Account of Tractarian Nonsense" (Philosophical Investigations). 
wrongdoers from committing more crimes, and possibly deterring them from repeating their crimes after they are released (and possibly deterring others too). The value of these consequences "outweighs" the pain of the punishment. The consequentialist approach to punishment appears to give hard determinists a way to justify whatever punishments are really needed to keep society functioning.

But remorse cannot be given an adequate consequentialist justification. Sometimes remorse has beneficial behavioral consequences, but sometimes it does not. The cases in which it does not have beneficial behavioral consequences pose a problem for hard determinism. As I will go on to argue, remorse is connected in a privileged way with understanding that one has done something wrong. For this reason, it is important for hard determinism to accommodate remorse even when it does not have beneficial behavioral consequences. This is a challenge for hard determinism, but I will argue that it can be met if we incorporate virtue ethics into hard determinism. ${ }^{3}$ I will conclude by arguing that the virtue-based account of remorse to be presented here is defensible even if we suppose that we do have free will after all. In other words, though hard determinism requires this account of remorse, this account of remorse does not require hard determinism.

To begin, we must consider how remorse functions when it does have beneficial behavioral consequences. First, remorse can modify wrongdoers' behavior so that they do not repeat wrongful acts in the future. ${ }^{4}$ Second, remorse can prompt wrongdoers to behave in special ways toward the people they have wronged, for example, by trying to make amends, and by expressing their remorse. ${ }^{5}$

First, remorse can prevent wrongdoers from repeating wrongful acts because experiencing suffering as a result of acting in some particular way tends to modify agents' behavior so that they do not act in that way again. We can see this phenomenon in its simplest form in the way a child who feels pain after touching a hot stove does not touch hot stoves again afterwards.

We can think of remorse as operating in a similar way. Remorse is a state of emotional suffering that is consciously focused on morally relevant facts about one's wrongful actions. Said differently, it is suffering that has those morally relevant facts as intentional objects, such that one suffers from the consciousness of one's wrongful actions. One cannot experience remorse without consciously representing morally relevant facts about one's wrongful actions as the cause of one's suffering. ${ }^{6}$ (For the moment, let us leave open the questions of what the morally relevant facts are, which are the intentional objects of remorse, and what the nature of the suffering involved in remorse is.) 
Remorse's privileged connection with morally relevant facts about one's wrongful actions makes remorse different from other kinds of suffering wrongdoers often experience as a result of those actions. Consider imprisonment. Prisoners can experience the suffering of imprisonment without thinking of it as caused by the crime that got them into prison. Prisoners often come to think of their imprisonment as caused by the prison guards, the police, and the courts-that is, the penal system. And it would seem that the more prisoners think of their imprisonment as caused by the penal system, rather than by their crimes, the less likely imprisonment will be to keep them from repeating their crimes. That is, if they think of imprisonment as caused by the penal system rather than by their crimes, they may believe that the best way to stay out of prison is to stay away from the penal system rather than to stop committing crimes.

The suffering of remorse cannot be psychologically dissociated in this way from the unethical action that is its original cause. And it is natural to assume that, all things being equal, the more clearly human beings understand the causal relationship between something that causes suffering and the suffering that thing causes, the more they will tend to avoid the thing that causes suffering. For this reason, remorse might be thought to be among the most effective kinds of suffering for preventing wrongdoers from repeating their wrongful actions.

Now let us turn to the second way remorse can produce beneficial behavioral consequences. Remorse can cause wrongdoers to behave in special ways toward the people they have wronged. Remorse can cause a wrongdoer to try to alleviate the suffering of the people he has wronged, that is, to try to make amends. Remorse can also cause a wrongdoer to express his remorse to the people he has wronged. The wrongdoer thereby communicates the fact that he is suffering from the wrong too, and thereby bears the burden of the wrong along with them. (This is of course merely a metaphor, but it is indispensable for thinking about remorse.) Often, when the people wronged feel that the wrongdoer bears the burden of the wrong along with them, it makes their own suffering easier to bear.

At this point we can consider the kind of remorse that poses the challenge for hard determinists, that is, remorse that does not have beneficial behavioral consequences. Remorse sometimes has an effect on the wrongdoer's inner life but no effect on the wrongdoer's outward behavior. Wrongdoers sometimes feel remorse, and form intentions to mend their ways in response to that remorse, but fail to act on those intentions. Also, wrongdoers do not always have the opportunity to make amends or express their remorse. But when remorse does not have any "payoff" in beneficial behavioral consequences, there isn't anything to "outweigh" the pain of the remorse, so a 
consequentialist justification cannot be provided. How can hard determinists hold that it is appropriate for wrongdoers to feel the pain of remorse if it has no beneficial behavioral consequences and wrongdoers do not deserve to experience this pain?

Hard determinists might just accept that it is not appropriate for wrongdoers to experience remorse if it has no beneficial behavioral consequences. But this is unsatisfying, because of the connection between experiencing remorse and understanding morally relevant facts about one's wrongful actions. Other forms of suffering that wrongdoers might experience in response to their wrongful actions do not seem to be linked to understanding that one has done wrong in any special way. Wrongdoers can be made to feel physical pain and fear, for example, without understanding why what they did was wrong. This cognitive relationship between remorse and morally relevant facts makes the preservation of remorse within hard determinism of special interest. Determinism doesn't imply that we shouldn't understand our wrongs, even if it does imply that we do not deserve to suffer for our wrongs. So if part of understanding that we have done something wrong is feeling remorse, then it might be appropriate to feel remorse when we have done something wrong, even if we do not deserve to feel remorse.

But is it in fact true that remorse is part of understanding that we have done something wrong? Retributivists about remorse are likely to object here. A retributivist might argue that understanding that one has done wrong and feeling remorse are entirely separate. We feel remorse when we understand that we've done wrong only because we believe that we deserve to feel remorse when we do wrong. Retributivists might hold that we can explain what makes wrong acts wrong in deontological terms, as the violation of absolute moral rules. They might then point out that, presumably, one can understand that one has broken rules without experiencing remorse, so we must provide an explanatory link between understanding that one has done wrong and remorse. Such a link, they might claim, can only be provided by the belief that one deserves to suffer when one has done wrong.

If this is the right way to think about remorse, then it appears that, when hard determinists reject desert, they break the connection between understanding the wrong and feeling remorse. But the retributivist's argument depends on stipulating that it is sufficient for understanding that one has done wrong to understand that one has broken moral rules. It is not obvious that the retributivist is entitled to this stipulation. If the hard determinist can provide a defensible alternative account of understanding that one has done wrong, according to which such understanding involves remorse, but not by way of 
desert, then the retributivist's argument gets no purchase. Let us turn to this task.

The first step is to claim that in order to understand that one has done wrong, one must understand that one has caused the people one has wronged to suffer. ${ }^{7}$ That is, the facts about the suffering one has caused are the intentional objects of remorse, according to the hard determinist, virtue-based account of remorse to be advanced here. A more abstract grasp of the fact that one has done wrong, a mere grasp of the fact that one has broken moral rules, is not sufficient for this kind of understanding.

The second step is to claim that virtuous wrongdoers sympathize with the suffering of the people they have wronged. What it is to sympathize with the wronged person, in the sense I have in mind, is just to suffer in sympathy with the wronged person. To return to the metaphor we used earlier, by suffering in sympathy, the wrongdoer bears the burden of the wrong along with the person wronged. This sympathetic suffering explains why remorse is painful, according to the account of remorse to be advanced here. In response to this second step, however, retributivists will surely claim that it cannot be appropriate to demand such sympathetic suffering if the wrongdoer does not deserve to suffer.

This leads us to the third step, which is to point out cases where we clearly do think sympathetic suffering is appropriate even when it is not deserved and to argue that we can think about remorse in terms of these cases. Sympathetic suffering is also characteristic of love and friendship. If one's loved one or friend is suffering, it is appropriate to suffer in sympathy. But the reason it is appropriate has nothing to do with desert. It would be a confusion to suppose that, by loving or befriending someone, one had gotten oneself into a situation where one deserved to suffer when that person was in pain. The reason we suffer in sympathy with friends and loved ones is that we care about them, and the sheer fact of understanding that they are in pain gives us pain. ${ }^{8}$ We think it is virtuous to love and befriend others, so if suffering in sympathy with friends and loved ones is part of loving and befriending, then it seems right to see such sympathetic suffering as partially constitutive of these virtuous states of character.

We can think of remorse as having the same underlying structure that suffering in sympathy with friends and loved ones has. Sympathetic suffering for friends and loved ones often has beneficial behavioral consequences that run parallel to the beneficial behavioral consequences of remorse. Sympathetic suffering prompts us to try to relieve the suffering of the friend or loved one, much as remorse prompts wrongdoers to try to make amends. Sympathetic suffering also prompts us to express our sympathy, to indicate that we bear the burden of the pain 
along with our friend or loved one, thereby making the burden of the friend or loved one easier for him to bear.

Sympathetic suffering for friends and loved ones also shares with remorse the fact that it doesn't always have beneficial behavioral consequences. But when it doesn't have such consequences, we still think it is appropriate. If you were stuck on a desert island, for example, and you knew someone you loved was suffering, you wouldn't think you should stop suffering in sympathy just because you couldn't help your loved one or express your sympathy, because suffering in sympathy is part of what it means to love the person. You could only stop suffering in sympathy if you stopped loving the person.

The reason we never seek a consequentialist or retributivist justification of sympathetic suffering for friends or loved ones and we do sometimes seek such a justification for remorse, is that we do not think of sympathetic suffering for friends and loved ones as a kind of punishment, and we are sometimes mistakenly inclined to think of remorse that way. So part of the solution to our problem about remorse is to stop thinking of it as punishment and, instead, to think of it as just one member of a set of emotional engagements, all of which depend upon suffering in sympathy with others, and none of which involve desert. Like love and friendship, remorse is a virtuous state of character that depends upon suffering in sympathy with people one cares about. ${ }^{9}$

It may be thought oxymoronic to speak of a virtuous state of character of an agent who has acted unethically. To this we can reply that, certainly, a perfectly virtuous person would be one who had no unethical deeds to feel remorseful about. But in the realm of the sub-ideal traversed by most of us, we must rely on a conception of imperfect virtue. ${ }^{10}$ That is, most of us are imperfectly governed by the virtues, so that we lapse from time to time and behave in ways that are not virtuous. Imperfectly virtuous agents feel remorse in the wake of serious lapses in virtuous conduct.

The relationship established when one agent wrongs another is of course a very different kind of relationship than what is involved in love or friendship. But it involves a sort of intimacy all the same. Loving, befriending, and harming all create what we might call moral connection. In all three kinds of relationship, the lives of the people involved become intertwined in fundamental ways, and the relationships contribute to the basic fabric of the moral identity of the people involved. The wrongdoer's subsequent experience of remorse is a way of recognizing and taking seriously the morally salient relationship he bears to the person wronged. Such sympathetic suffering is something we expect of wrongdoers, in much the same way that we expect sympathetic suffering from people whose loved ones or friends are suffering. 
Some might object that there isn't the right kind of analogy between love and friendship, on the one hand, and remorse on the other. When we suffer in sympathy with loved ones or friends, we do so spontaneously, because we care about them. But when one person wrongs another, the wrongdoer obviously doesn't care about the person, at least not enough to avoid the wrongful action in the first place. So, with love and friendship, the sympathetic suffering springs from an emotional engagement that is already there, on the basis of which one spontaneously suffers in sympathy. But when wrongdoers do not suffer remorse, it means that there is no emotional engagement that could be the basis for spontaneously suffering in sympathy. To claim that remorse has the same structure as suffering in sympathy with friends and loved ones is to seek to force remorse into a mold it just doesn't fit.

But this objection is mistaken. Often, wrongdoers do feel remorse just as spontaneously as people suffer in sympathy with friends and loved ones. No one has to demand it of them. It is true that, in many cases, the emotional engagement between the remorseful wrongdoer and the person wronged only forms after the wrong is done ${ }^{11}$ while in cases of suffering in sympathy with friends and loved ones, the emotional engagement often preexists the suffering with which we sympathize. But this does not undermine the account presented here. The central idea to be advanced here is that the experience of remorse is a lot like the wrongdoer feeling friendship or love for the person wronged in the wake of the wrongful act, and then suffering sympathetically on the basis of an emotional engagement similar to the one found in friendship and love.

Now, however, objectors will ask, what about cases where wrongdoers do not spontaneously suffer sympathetically? It is basic to our understanding of remorse that it is something we expect of wrongdoers, so that when they do not feel remorse, they are failing to do something we want them to do. Objectors may claim that there is no parallel in love or friendship. We suffer in sympathy with people we care about, but when we do not care about someone, we do not have that special reason to suffer in sympathy with him, and no one can expect us to suffer in sympathy.

But this objection is also mistaken because there are cases in which we expect sympathetic suffering from someone who doesn't care about the person suffering, that is, cases in which it would be virtuous for the person to care, and in which the person's failure to care manifests a lack of virtue. ${ }^{12}$ Consider two people, call them Jones and Green. We tell Jones that if he were virtuous, he would suffer in sympathy with Green, but he rejects our demand by claiming not to care about Green. If Green is Jones's significant other, or parent, or child, or mentor, or someone with whom he has played bridge every weekend for 
years, then we can reply to Jones by saying that it would be virtuous to care about Green, and since caring about Green involves suffering in sympathy, it would be virtuous to suffer in sympathy with Green, and by failing to do so, Jones manifests a lack of virtue. The point here is that there are privileged ways of interacting with other people that create expectations that one care about those other people. ${ }^{13}$ And my claim is that wronging someone is among these privileged ways of interacting.

Here is another way of thinking about the same point. Suppose one was talking with someone one didn't know well, call him Smith. Suppose Smith mentioned that his significant other of ten years was suffering terrible pain from an illness. And suppose one said how sorry one was to hear about it, that it must be a very painful time not just for Smith's significant other, but for Smith too. And suppose Smith responded, "Why would it be a painful time for me? I'm not the one with the pain." One would presumably feel that Smith's failure to suffer sympathetically made him callous, or even monstrous. What I want to suggest is that the callousness we find in wrongdoers who have committed, for example, serious crimes of violence and who feel no remorse is not fundamentally different from Smith's callousness. ${ }^{14}$

Sympathetic suffering is of course not all there is to remorse. Remorse is a unique kind of sympathetic suffering, because in remorse we sympathize with suffering we have caused. And it is this special feature of remorse that sometimes causes the wrongdoer to modify his behavior so as to not repeat his wrongful actions. But this is not a problem for our account. We need not claim that remorse shares all its features with sympathetic suffering for friends and loved ones, only that what is painful about remorse can be understood as based on a similar sort of sympathetic suffering. And remorse need be no less effective as a behavior-modifier when it is based on suffering in sympathy with the person wronged than it would be if it were based on suffering retributively self-imposed. The idea is that remorseful wrongdoers modify their behavior so as to have less suffering to sympathize with in the future.

This last point must be underlined, because it sheds light on another unique feature of remorse. It must be emphasized that modifying one's behavior so as to have less suffering to sympathize with in the future is vicious in all cases except those in which one might cause the suffering oneself. It is cowardly to avoid befriending and loving people who are suffering in order to avoid suffering in sympathy with them. ${ }^{15}$ It is only virtuous to avoid forming relationships in order to avoid sympathetic suffering in cases of wronging others, that is, in cases where the suffering of the other would be caused by the very fact of establishing the morally salient relationship with the other that would be the foundation of one's sympathetic suffering. ${ }^{16}$ 
Retributivists may weigh in again at this point, and object that the emotion that remains when we exclude the concept of desert from remorse isn't really remorse at all, because as a matter of empirical fact, the emotion that we refer to as remorse in contemporary society does involve the idea that one deserves to suffer for one's wrongs. I do not think this is always true. But suppose it is. It need not undermine this account. We can think of hard determinist, virtue-based remorse as a kind of remorse with most of the same features of remorse that are experienced in contemporary society, but not all of them, that is, not the features that depend on the concept of desert. Hard determinist remorse would seem to preserve the most important features of remorse as experienced in contemporary society. It is emotional suffering involved in wrongdoers' understanding of their wrongful acts that allows them to bear the burden of the suffering they have caused along with the people they have wronged, and it sometimes has beneficial behavioral consequences. In a hard determinist society, the kind of remorse defended here could play a role which is very similar to the role played by remorse in contemporary society. Further, if remorse based on sympathetic suffering is more virtuous than remorse based on retributively self-imposed suffering, then the presence of remorse based on retributively self-imposed suffering in contemporary society would not serve as an argument against the sympathetic suffering account, but would rather demonstrate that contemporary society is not as virtuous as it could be. (We will later consider arguments that point in this direction.)

Retributivists may also object that remorse normally involves regret that one acted wrongly, and regret only makes sense if one had free will in acting wrongly. But this is mistaken. It is uncontroversial that regret involves a wish that one had not acted wrongly. But it is not obvious that this wish must be based on a belief that it was physically possible for one's wrongful action not to have occurred, in any sense that would conflict with hard determinism. ${ }^{17}$ People often wish for things that are physically impossible, without falsely believing that those things are physically possible. For example, I may know that it is physically impossible for me to lift a 200-pound weight but still wish to do it. It is also important to note that people often express regret by saying that they wish to "go back and undo" the regretted deed. But the time travel which would be required to fulfill this wish is presumably physically impossible no matter how things stand with determinism, and it would be implausible to suppose that people who express regret in this way believe such time travel to be physically possible. So it seems unreasonable to use the physical possibility of fulfilling the wishes involved in regret as a criterion for the adequacy of accounts of regret. 
Since we are seeking to explain remorse on the model of suffering in sympathy with friends and loved ones, it may be instructive to look for a parallel to regret in sympathetic suffering for friends and loved ones. And such a parallel is readily available: when one suffers in sympathy, one normally wishes that the event that caused the friend or loved one to suffer did not occur. Suppose it is a naturally occurring event, a falling rock, for example: one wishes that the rock had not fallen. One can coherently wish the rock had not fallen even if one knows the rock was deterministically necessitated to fall. On the current account, the pain accompanying regret over striking someone without justification (for example) is not essentially different from the pain accompanying the wish that the rock had not fallen. We can hear "If only I had not struck him!" in the same way that we hear "If only the rock had not fallen!" One can of course only feel regret for one's own actions, but there is no reason to suppose that hard determinism would undermine the distinction between events that are one's own actions and events that are not.

Let us proceed to a different sort of objection. According to the account advanced here, the suffering of remorse can be valuable even without a consequentialist justification. But retributivists may object that this makes such suffering intrinsically valuable, that is, that it makes it an end in itself. Retributivists may argue that this can only be a coherent position if wrongdoers deserve to suffer. But a virtue-based hard determinism must reject the claim that nonconsequentially justified remorse is an end in itself. Remorse is a noninstrumental means to the end of virtue, in the sense that it is a part of the whole of an (imperfectly) virtuous state of character of an agent who has acted unethically. We can refer to this kind of means as a constitutive means.

It may be objected that the means/end relation is inherently instrumental, making it a contradiction in terms to speak of noninstrumental means to ends. But this is a merely terminological objection. The distinction could be recast as a distinction between two kinds of instrumental means: one that is a mere cause of the end and not part of what makes the end valuable and another that partially constitutes the end and its value.

When remorse is consequentially justified as a means to the end of beneficial behavioral consequences, in the sense we have discussed here, the end is the behavioral consequences. Remorse is represented as a mere cause of the behavior, not part of what makes the behavior valuable. That is, the suffering of remorse must be "outweighed" by the value of the behavioral consequences if remorse is to be consequentially justifiable: rather than being a part of what makes the end valuable, it factors into the consequentialist cost/benefits equation in a way that 
diminishes the overall value of the end. The virtue-based justification of remorse without beneficial behavioral consequences requires a conception of virtuous character that is not necessarily expressed in behavior. In the virtue-based justification, the end is the virtuous state of character, and remorse is a means to this end in the sense that it is a part of the end, not a mere cause of the end.

I by no means wish to rule out some sort of functional account of behaviorally unexpressed remorse and its contributions to virtuous character, for example, an account based on the causal role of remorse in producing certain courses in the agent's reflections and certain emotions in response to certain thoughts. In this way we could explain remorse's function as a constitutive means in straightforwardly causal terms, so long as none of the effects with respect to which remorse's causal role was defined were necessarily expressed in behavior, and so long as we recognized remorse as partially constitutive of the overall virtuous state of the agent's character. (Remorse can be a cause without being a mere cause.)

Now I want to compare this account of remorse to two other accounts of moral psychology in recent literature on moral responsibility, one from Hilary Bok and the other from Bernard Williams. Neither Bok nor Williams focus on remorse: Bok defends the role of guilt in moral psychology, and Williams defends the role of shame in moral psychology. But their concerns overlap in important ways with those of this paper. Remorse, guilt, and shame are all painful moral emotions, and they have all commonly been thought to play fundamental roles in moral psychology. And both Bok and Williams are concerned with the relationship between moral responsibility and painful moral emotions. Bok defends a kind of guilt that does not involve desert or self-retribution but does involve moral responsibility. Williams thinks we should reject moral responsibility, and should therefore reject guilt, and base moral psychology on shame instead. I will argue that remorse as it has been explained here is a better foundation for moral psychology than either Bok's guilt or Williams's shame.

The present paper grants a fundamental role in moral psychology to a kind of remorse that is intrinsically otherdirected, in the sense that the pain of remorse arises from sympathizing with others. But as we have discussed, it is common to represent remorse as intrinsically self-directed. Selfdirected accounts standardly depict remorse as self-retribution. Hilary Bok, however, presents an account of guilt that is selfdirected, but not retributivistic, in the context of a compatibilistic theory of free will. ${ }^{18}$ Bok compares the experience of guilt to the loss of a romantic love relationship. She claims that seeing guilt this way can help one understand guilt without supposing that we feel guilty because we believe we deserve to. 
There are two important objections to her account that must be made from the perspective of the present paper.

First, by drawing an analogy between guilt and the pain of losing romantic love, Bok produces an account of guilt that makes it seem narcissistic. Bok conceives guilt as a sorrowful consciousness of how one's wrongful act has stained one's moral character. But it seems vain (and therefore vicious) to focus on the stain upon one's character instead of harms done to others. When a relationship of romantic love comes to an end, the consequent suffering is based on one's own loss and is normally bound up with a sense of rejection and diminished self-esteem. The analogy Bok draws between the loss of romantic love and guilt over one's wrongful actions implies that feeling guilty because one has done wrong is something like falling out of love with oneself because one has not lived up to one's moral image of oneself. This portrays guilt as a self-focused experience characterized by sorrow over the diminished self-image available to the wrongdoer. In psychoanalytic terms, it makes guilt a kind of narcissistic injury. Such self-focus seems in tension with sincere appreciation of how one has harmed others. So, if we find it natural to account for what seems virtuous about painful moral emotions in terms of how they draw our attention to the harm we have done to others, we should resist counting Bok's sort of guilt among the virtues. ${ }^{19}$

The second objection to Bok's view involves the concept of desert, and the debate between compatibilism and hard determinism. Bok draws the analogy between guilt and the pain of losing romantic love in order to explain guilt without appealing to the concept of desert. She holds that a wrongdoer's guilt is appropriate not because he deserves to feel guilty but, rather, because feeling guilt when one has done wrong is appropriate in the same way that feeling pain upon the loss of a romantic love relationship is appropriate. Insofar as Bok's work and this paper both seek to provide nonretributivistic accounts of painful moral emotions, they have a common purpose. But Bok does this within the context of a compatibilistic account of free will. Detaching the appropriateness of guilt from desert seems like a dangerous course for a compatibilist, given the strong connections between the concepts of desert and moral responsibility. That is, if we do not need the concept of desert to explain the appropriateness of guilt, why do we need the concept of moral responsibility as part of our theory? And if a theory does not need the concept of moral responsibility, then isn't it really hard determinism masquerading as compatibilism?

Now let us briefly consider Bernard Williams's moral psychology. ${ }^{20} \mathrm{He}$ thinks that a greater reliance on the concept of shame in accounts of the moral emotions can help make up for the weaknesses he sees in the concept of moral responsibility. His concerns about moral responsibility stem not from worries 
about determinism but from the phenomenon of "moral luck," and problems such as the alleged characterlessness of the moral self in Kantian approaches to moral psychology. Williams's view is that guilt is the central emotion of self-reproach in societies where moral psychology is regulated by the concept of moral responsibility and that shame is the central emotion of selfreproach in societies that predate the influence of the concept of moral responsibility. He seems to think that, in general, providing a greater role for shame in moral psychology would have a corrective effect on philosophical ethics.

From the perspective of this paper, we can agree with Williams that the concept of moral responsibility is metaphysically problematic, and we need not object to his suspicions about guilt. But if we can demonstrate the appropriateness of remorse in the absence of moral responsibility, as we have sought to do in the present paper, then it is not clear that we would have reason to give shame an expanded role. On Williams's account, "What arouses shame is what typically elicits from others contempt or derision or avoidance." 21 But (to speak bluntly) it seems reasonable to claim that sensitivity to others' expectations that we feel remorse could be a virtue, and it seems much less reasonable to claim that sensitivity to others' contempt, derision, and avoidance could be a virtue. If contemporary moral consciousness tends to be more thickskinned with respect to contempt, derision and avoidance than ancient moral consciousness, this would seem to be a mark of moral progress. One way of explaining such thick-skinnedness might be vulnerability to others' expectations about remorse but not to their contempt, derision, or avoidance. If we can detach the concept of remorse from the concept of moral responsibility, then we can reject the concept of moral responsibility without needing shame to prop up the foundations of moral psychology.

Our goal in this paper has been to accommodate remorse within hard determinism. The virtue-based account of remorse we have developed emphasizes a structure that is shared by remorse on the one hand, and sympathetic suffering felt toward friends and loved ones who are in pain, on the other. In both cases, we suffer because we sympathize with people we care about. Rejecting the concept of moral responsibility would give us no reason to stop suffering in sympathy with friends and loved ones. So if we can understand remorse in terms of the same underlying structure, we should not suppose that rejecting the concept of moral responsibility would give us reason to stop feeling remorse.

To conclude, it should be noted that the account of remorse advanced here is defensible even if we do have free will. If we find it natural to account for what seems virtuous about painful moral emotions in terms of how they draw our attention to the 
harm we have done to others, then an account of remorse based on sympathetic suffering seems preferable to an account of remorse based on suffering retributively self-imposed, no matter how things stand with the metaphysics of free will and moral responsibility. Said differently, if it is virtuous to feel remorse that involves sympathetic suffering, then this is an argument on behalf of such remorse, whether or not we have free will. And if the virtue of self-retributive remorse is questionable, then this is an argument against self-retributive remorse, whether or not we have free will. So even if we suppose that there are no metaphysical obstacles to the concepts of moral responsibility and desert that are involved in the retributivist account of remorse, there are ethical obstacles to the retributivist account that favor the virtue-based sympathetic suffering acocunt presented here. ${ }^{22}$

\section{Notes}

Thanks to the following for helpful discussions and suggestions: Erin Kelly, Michael Slote, Steve Davis, Anne Tarver, Candace Vogler, Amy Kind, Chad Flanders, Michael Green, and the audiences at Augustana College and at the Mountain-Plains Philosophy Conference at Fort Hays State University, where earlier verions of this paper were presented in 2004. I claim full credit for any remaining errors.

1 A brief explanation of hard determinism, as it will be understood here, may be helpful. Hard determinists are incompatibilists about moral responsibility and determinism. Incompatibilists hold that an agent is morally responsible for an action, that is, is praiseworthy or blameworthy for an action, only if the agent could have acted differently than he actually acted; they hold further that if determinism is true, then no agent could ever have acted differently than he actually acted. Hard determinists hold that determinism is true, and they conclude that agents are not morally responsible for their actions. Three further points may also be useful.

First, hard determinists can accept that events at the quantum level are indeterministic. They need only deny that we have reason to believe that microphysical indeterminacy "propagates upward" to the macrophysical level in ways that are significant for human actions. That is, hard determinists can hold that human actions are deterministic, for all intents and purposes, even if there is quantum indeterminacy.

Second, when hard determinists deny that we are morally responsible for our actions, they do not mean that there is no distinction between justified and unjustified actions. They only mean that agents are not praiseworthy or blameworthy for acting as they do. That acting in some way would be unethical can be a reason against acting in that way, even if one would not be blameworthy for acting in that way. (If "ought" implies "can," then hard determinism implies that we never fail to do anything we ought to do because according to hard determinism, it is only possible for us to do what we actually do. This means that if someone lies, we cannot criticize her by claiming that she ought to have told the truth. But this does not imply that hard 
determinism cannot offer any moral criticism of her lie. Hard determinists can point out that she was mendacious and, therefore, vicious, without claiming that she ought to have told the truth, and without claiming that she is blameworthy for having been mendacious. And the fact that lying would be vicious can be a reason against lying, even if it is not true that one ought to tell the truth. Also see note 12.)

Third, it can seem that, if determinism is true, it makes no sense to deliberate about what we should do. It can seem that our deliberations have no effect on our actions because it is inevitable that we are going to act in a certain way, so there is no point in worrying about what is right and wrong anyway. But that impression is mistaken. Suppose a habitual shoplifter who is trying to break his habit is in a store confronting two options: to shoplift a book or to put it back on the shelf. And suppose he reasons that it would be best to put it back, and puts it back. Even if determinism is true, and it is therefore inevitable that he will decide to put it back, his decision to put it back is nonetheless a part of the causal sequence that terminates in his putting it back, just as much as his arm moving to put it back is a part of the causal sequence. It is not as though some other process causes him to put it back and prevents his reasoning from having an effect. So good moral reasoning can still be a cause of good actions and, therefore, still has a point, even if determinism is true.

2 It is important for the account to be developed here that one can be a consequentialist about punishment without being a consequentialist about ethics as a whole. The goal in this paper is to incorporate a circumscribed consequentialism about punishment into an account based more broadly on virtue ethics. (For a different approach to ethics in the absence of desert, which also gives consequentialist thinking a role within a nonconsequentialist theory, see Erin Kelly's "Doing Without Desert," Pacific Philosophical Quarterly 83 [2002]: 180-205.)

3 Michael Slote notes that virtue ethics would remain viable if determinism is true. But he does not consider virtue ethics as a foundation for remorse ("Ethics Without Free Will," Social Theory and Practice 16, no. 3 [1990]: 369-83).

4 Behavior modification is not incompatible with hard determinism. There can be patterns in behavior that persist over intervals and then change, even if determinism is true. Changes in pattern would be deterministically necessitated, of course, but this does not prevent us from identifying patterns and changes in them.

5 This list is not intended to be exhaustive. The two ways discussed here are the two that are important for the argument to be made here, and certainly they must figure among the most important in any analysis.

6 Two caveats: (1) For the sake of simplicity, I am discussing remorse based on true beliefs about one's actions. Sometimes people feel remorse on the basis of false beliefs-that is, they believe some action of theirs was unethical but it was not, so the action in fact gives them no reason to feel remorse. But this does not undermine our claims about the privileged connection between remorse and morally relevant facts because even erroneous remorse must be based on what the agent takes to be morally relevant facts. (2) Though we 
think of morally relevant facts about wrong actions as reasons for remorse as well as causes of remorse, I am emphasizing the causal dimension because what is special about remorse as a behavior modifier is brought out most clearly in causal terms.

7 It may be objected that there are wrongs that cause no suffering. For example, I might wrong someone by lying to him, even if it was impossible that it could ever bring him suffering. But this is not a problem for the present account, since it is not clear that remorse would be demanded of me in such cases. A recognition of my flaws, and a resolution to be honest in the future, might be sufficient. The virtuebased account to be advanced here can identify what is problematic about such an act of lying without appealing to its effects on the person wronged, by identifying the act itself as mendacious. (Thanks to Steve Davis for raising this objection.)

8 Michael Slote develops a virtue ethics based on caring but does not apply it to hard determinism or remorse (Morals from Motives [New York: Oxford University Press, 2001]). Generally speaking, the perspective on virtue taken in this paper fits more naturally with the sentimentalist approach to virtue ethics found in Hume and Hutcheson and developed in the contemporary context by Slote, than it does with Aristotelian approaches to virtue ethics. So the account of remorse developed here is likely to be more congenial to a sentimentalist approach than to an Aristotelian one.

9 We need not claim that remorse is always virtuous: people may feel deep remorse in the wake of minor wrongs, or may become debilitated by remorse, and there is no need to recognize these cases as virtuous. Similarly, one can suffer too much when sympathizing with a friend or loved one, and the criteria we use for determining when suffering is excessive would seem to be much the same for remorse and for sympathetic suffering for friends and loved ones. (Thanks to Steve Davis for an objection that prompted this point.)

${ }^{10}$ Patricia Greenspan argues that feeling guilt is not incompatible with being virtuous. She does not make such a case for remorse, but her argument can be easily extended to cover remorse ("Guilt and Virtue," Journal of Philosophy 91, no. 2 [1994]: 57-70).

${ }^{11}$ This is of course not true in all cases. Sometimes we act wrongfully toward people we already care about.

${ }_{12}$ To claim that a failure to care can manifest a lack of virtue need not commit one to the claim that the uncaring agent ought to care or that the agent in any other sense has "external reasons" to care (though it is of course compatible with these further commitments). This is important for the following reason: though it is often thought that "ought" implies "can," hard determinists hold that we never can do anything other than what we in fact do. Hard determinists can explain the significance of a lack of virtue without appealing to "oughts" as follows. Virtuous people want other people to be virtuous too, so virtuous people have a reason to cause other people to be virtuous. In cases where someone's failure to care manifests a lack of virtue, virtuous people have a reason to cause that person to care, for example, by describing the suffering of the other to him, or by describing his morally salient relationship to the other, in a way that prompts his sympathy. We need not appeal to "oughts" to make out any of these claims. (Also see note 1.) 
${ }^{13}$ I am not claiming that we never have reason to care about people with whom we do not have morally salient relationships. But if we are thinking of caring as constituted by occurrent emotional states having facts about particular people as intentional objects, then it would seem to follow that even the most virtuous people cannot care for more than a limited number of people, given the limited time people have to care. And it seems correct to say that the people about whom virtuous people care in a particularistic way are those with whom they have morally salient relationships. We may also expect virtuous people to care in a nonparticularistic way for human beings in general, and since this sort of caring would not have facts about individuals as intentional objects, it would not be confined to a limited group of people. But suffering in sympathy is normally based on particularistic caring. See Slote (ibid.) for a discussion of the distinction between particularistic and generalized caring.

${ }^{14}$ This account of remorse might be framed in terms of empathy rather than (or in addition to) sympathy. I frame it in terms of sympathy because of affinities between the perspective on virtue taken here and Hume's account of virtue, in which sympathy occupies a central position. Recent work on empathy which supports this approach to remorse includes Martin Hoffman's Empathy and Moral Development (New York: Cambridge University Press, 2000) and Michael Slote's "Sentimentalist Virtue and Moral Judgement: Outline of a Project" (Metaphilosophy 34, no. 1 [2003], 131-43).

15 There are some exceptions to this claim about cowardice. One might avoid befriending people who engage in needlessly risky behavior in order to avoid sympathetic suffering without being a coward. One might also avoid befriending someone in order to avoid sympathetic suffering without being a coward if one had reason to believe that the sympathetic suffering would be debilitating because of limits in one's psychological strength. But even in these cases, it seems implausible to suppose that this avoidance would be virtuous. It would simply not be vicious. (Thanks to Anne Tarver fo this objection.)

${ }^{16}$ It is also noteworthy that it is only if we explain remorse in terms of sympathetic suffering that the pain of remorse can give one a broadly moral, rather than merely self-interested, reason to modify one's behavior. If an agent with a history of violent behavior knows he will be beaten if he continues to harm others, then his desire to not be beaten gives him a reason to modify his behavior so as to stop harming others. But if this is the only reason that motivates him to modify his behavior, then it seems that his motivation is not really moral but rather merely self-interested. For his motivation to be moral in this case, he must be at least partially motivated by a concern for others. If we think of remorse as retributively self-imposed suffering, then a desire to not feel remorse seems no morally better as a reason to modify one's behavior than a desire to not be beaten. But if remorse is based on sympathetic suffering, then a desire to not feel remorse intrinsically involves a concern for others.

${ }^{17}$ Bernard Williams makes a point that parallels this one in some respects.

${ }^{18}$ Hilary Bok, Freedom and Responsibility (Princeton: Princeton University Press, 1998), 167-79. 


\section{Ben Vilhauer}

${ }^{19}$ This response to Bok fits well with Hutcheson's view that it is self-centered to concern oneself overmuch about one's own virtue, or lack thereof. (Thanks to Michael Slote for this point.)

${ }^{20}$ Bernard Williams, Shame and Necessity (Berkeley: University of California Press, 1993).

${ }^{21}$ Williams, Shame and Necessity, 90.

${ }^{22}$ Thanks to Michael Slote for suggesting this point. 
Copyright of Southern Journal of Philosophy is the property of Southern Journal of Philosophy and its content may not be copied or emailed to multiple sites or posted to a listserv without the copyright holder's express written permission. However, users may print, download, or email articles for individual use. 